\title{
Causal Relationships of Readability Risks in Construction Contracts
}

\author{
Kerim KOC ${ }^{1}$ \\ Asli Pelin GURGUN²
}

\begin{abstract}
Issues related to readability risks in contracts could exacerbate conflict, claim and dispute occurrences in construction projects. Determination of root causes of readability risks by defining casual relationships in construction contracts is essential to improve contract documentation and enable successful risk management. This paper aims to differentiate net causes from net effect factors of readability risks in construction contracts. Most significant readability risks in construction contracts were analyzed using fuzzy decision-making trial and evaluation laboratory (DEMATEL) method, which is known for its wide implementation in similar problems. Root cause degree (RCD) diagram was drawn to illustrate the differentiation of these factors by adopting maximum mean de-entropy (MMDE) algorithm. Analysis results indicated that poor grammar use, legal terminology, visual representation, and negative language were the major underlying cause factors; while lengthy document, use of abbreviations, scope complexity, controversial uses, repetitions, and ambiguous words were the net effect factors. The results are expected to improve readability of contract documents, which would contribute to more effective risk management and better allocation of project resources.
\end{abstract}

Keywords: Construction projects, contract readability, contract drafting, construction conflicts, risk management.

\section{INTRODUCTION}

The adversarial nature, lack of trust, inherent risks and excessive time pressures of construction projects contribute to the germination of conflicts, claims and eventually disputes [1]-[4]. Cheung and Yiu [5] conceptualized construction disputes as having three main components: contract provisions, triggering events and conflicts. Contract incompleteness with inadequate contract documentation, poor understanding of contracts

Note:

- $\quad$ This paper was received on July 6, 2021 and accepted for publication by the Editorial Board on November 29, 2021.

- Discussions on this paper will be accepted by May 31, 2020.

- https://doi.org/10.18400/tekderg.962928

1 Yildiz Technical University, Department of Civil Engineering, Istanbul, Turkey kerimkoc@yildiz.edu.tr - https://orcid.org/0000-0002-6865-804X

2 Yildiz Technical University, Department of Civil Engineering, Istanbul, Turkey apelin@yildiz.edu.tr - https://orcid.org/0000-0002-0026-4685 
and improper contract administration processes [6]-[9] are leading factors contributing construction conflicts, as supported by a recent Arcadis report [10]. When the contract is incomplete, its provisions can be interpreted differently by involved parties, then a conflict and dispute is inevitable [11]. Maqsoom et al. [12] addressed that construction disputes could be considered as one of the keys for inefficient performance of construction projects. Therefore, improving contract documents could be regarded as a preventative approach to dispute occurrence prior to project execution process.

Contracts play a significant role in assisting to meet project objectives as a control and coordination mechanism [13], especially in construction projects due to their inherent uncertain, complex and project-specific natures [4], [14]. However, construction contracts are usually comprised of set of documents that contain numerous provisions, specifications and requirements, making their administrations difficult for project engineers and managers. Smooth functioning of contracts can be achieved only with high degree of readability, simplifying contract documents, reducing ambiguities in responsibilities, and increasing commonality in the interpretation [15]. Project parties could fail to understand their responsibilities if the draft of contract is hard to read. In addition, they may seek to find flaw of contracts to behave opportunistically particularly when conflicts arise [11]. Therefore, proper contract drafting and administration are essential elements for successful achievement of project objectives [15], [16]. This brought significant attention from both scholars and practitioners to contract design problems recently [17].

The readability of construction contracts can be improved prominently by exploring the root causes and causal relationships of readability problems. Poor readability of a document can be regarded as one of the root causes of contract incompleteness, which has also been regarded as one of the main root causes of construction disputes [2]. Root cause could be defined as the fundamental and underlying reason of an undesirable event, which, could prevent the problem from occurring recurrently, if eliminated properly [18]. In addition, readability risks leading to poor contract documentation are strongly associated with each other, highlighting the requirement of differentiating cause factors from effect factors. For instance, while decreasing the number of words, the structure of sentences could become more complex with grammatical errors [19], [20]. On the contrary, many scholars have also addressed that long sentences could make contract less readable [1], [21], [22]. Therefore, analysis of the most causal factors affecting contract readability is essential to improve construction contracts, which is the main legal instrument that connects various parties with a legal bond [23].

Readability risks of construction contracts are seldom examined and underlying causes are rarely analyzed in the existing literature [24]. In construction risk management literature, it is very common to focus on contractual risks affecting operations as part of a general risk management plan in projects. However, this approach mostly focuses on operational risks due to contractual provisions and requirements. This paper aims to further examine the risks identified by Koc and Gurgun [25] by investigating the causal relationships among the most significant readability risks to deliver more effective contract administration and risk management. Fuzzy decision-making trial and evaluation laboratory (DEMATEL) method was adopted to determine the causal relationships. Mean plus standard deviation (MPSD) and maximum mean de-entropy (MMDE) algorithms were both used to determine threshold values to indicate individual relationships between readability risks and draw the 
root cause degree (RCD) diagram. By emphasizing the most effective measures to improve the quality of construction contracts, the findings of this study can be useful for contract drafters, dealing with traditional and standard contract forms such as the International Federation of Consulting Engineers (FIDIC) and New Engineering Contract (NEC), or contract modifications.

\section{RELATED WORKS}

Construction contracts are voluminous documents making it harder to read and extract required information whenever needed [26]. In fact, when any document is not readable hindering its intended meaning, there is just a little value of it [27]. High degree of comprehension can be achieved only when readability of the contract document is high [15]. Easy-to-read contract documentation is essential particularly with respect to construction contracts to minimize conflicts, claims, and disputes among involved parties [28].

In practice, traditional contracts are regarded to include more clarity issues compared to standard contract forms such as FIDIC or NEC [29]. Therefore, standard contract forms have been frequently used in the construction industry to reduce clarity and readability problems [30]. However, while adopting standard contract forms, various modifications in some clauses are made by clients to satisfy requirements of the projects [22]. Rameezdeen and Rodrigo [22] found that modifications to standard contract forms generally make the contracts more difficult to read. All these considerations require a thorough analysis of risk factors affecting readability of construction contracts for smooth contract administration. Existing literature mostly lacks systematic and overall assessment of readability risks and is not sufficiently contributing to the revelation of root causes regarding readability issues in standard forms and traditional contracts. Even studies that analyze readability of construction contracts are limited in the literature.

As examples of limited studies, Broome and Hayes [29] compared the clarity of traditional contracts and NEC, and found that while not being perfect, standard contract forms were more clear than traditional contracts. Rameezdeen and Rajapakse [15] investigated readability of FIDIC and NEC by using a readability formula to determine whether there was a relationship between readability and degree of commonality in interpretation and found a positive relationship. Chong and Zin [1] investigated the standard contract form in Malaysia, proposed measures to develop its language structure, and ranked those related to length of the sentences at top. Koc and Gurgun [25] investigated and prioritized readability risks in construction contracts based on their dispute potentials related to time, cost and quality criteria. Rameezdeen and Rodrigo [22] examined the impact of modification to standard contract forms on readability, and asserted that more than $50 \%$ of the original and modified contract clauses were still difficult to read. Besaiso et al. [2] compared the suitability of FIDIC and NEC standard forms in Palestine and addressed that NEC appears to be more capable than FIDIC to minimize disputes. Youssef et al. [31] assessed semantic risks of ad hoc and amended standard contract forms and found a strong correlation between contract risk rating and the magnitude of contingency included in the tender price of contractor. Lee et al. [32] proposed a proactive risk assessment model based on rulebased natural-language processing to detect missing contractor-friendly clauses in the 
modified FIDIC conditions by clients, and included some of the readability factors in the proposed automated model. Previous studies show that there is a gap in the literature about root cause analysis of readability risks.

\section{DETERMINATION OF READABILITY RISKS IN CONSTRUCTION CONTRACTS}

Fundamentally, readability can be defined as a function of a text and a reader. It is the integration of the structure, characteristics, and context of a text with the information processing features and abilities of a reader [27]. In this study, readability risk of a contract is defined as structural and textual issues in a contract that hinder comfortability in reading and inevitably diversify the interpretation of contract clauses. A structure of a typical need for reading a construction contract is illustrated in Fig. 1. Contract management can be typically defined in three phases: pre-award, award and post-award phases. In pre-award phase, involved parties plan, prepare the scope, develop the contract to offer required services, define responsibilities and allocate risks to meet contract provisions. Then in the award phase, project parties negotiate and sign upon agreement of the contract terms. Finally, in post-award phase, project managers monitor the performance to meet the requirements according to contract provisions without any flaws until the end of the projects. In case of any flaw, conflicts may arise and the readability of the contract becomes more speculative. Parties usually seek evidence to justify events based on their interests referred in contract provisions. Such opportunistic approaches sometimes lead to conflicts that may jeopardize successful completion of projects [33] and hinder effective long-term relationships [34]. Therefore, acceptable degree of readability of construction contracts is essential from the initiation to the termination of construction projects.

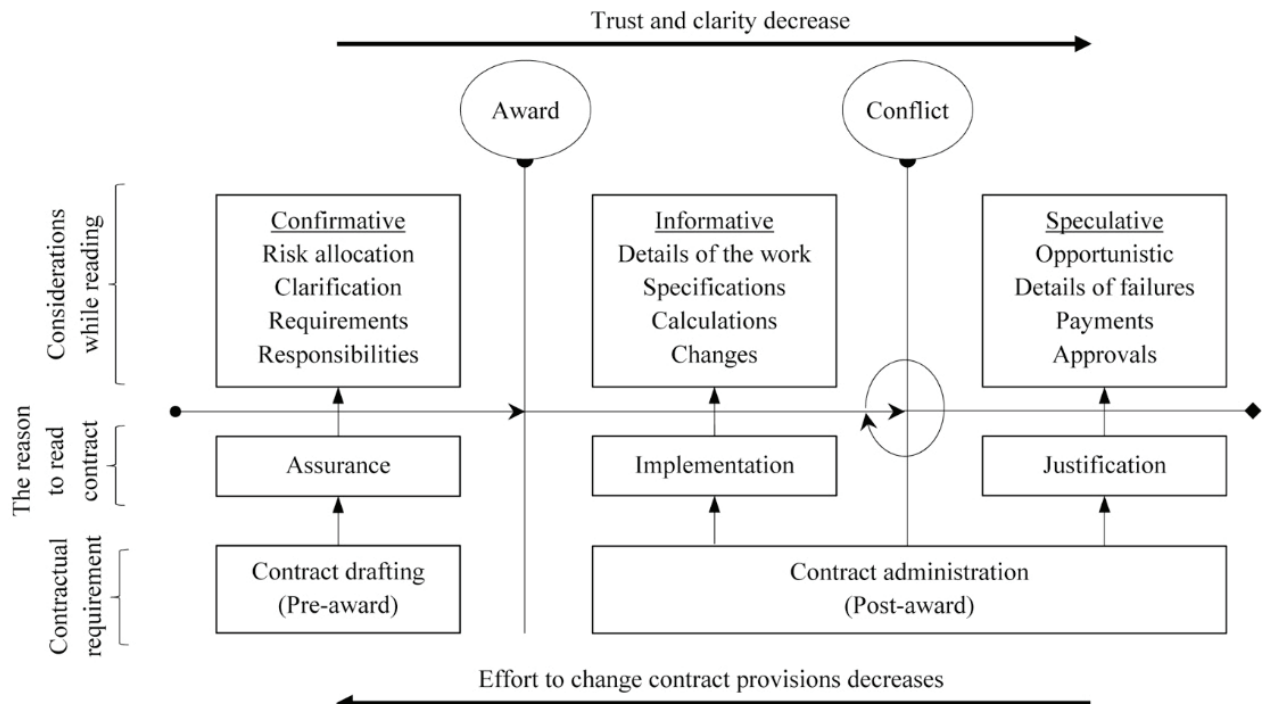

Fig. 1 - Generic structure of a typical need for reading construction contract. 
There are numerous factors affecting the readability of construction contracts. Koc and Gurgun [25] performed a comprehensive literature review accompanied by a pilot study to unveil readability risks in construction contracts, which resulted in 18 readability risks. These risks mainly included ambiguity, specialized vocabulary, length-related, legalese, inconsistency, layout, and grammatical structure. The researchers analyzed and ranked these risks by using fuzzy VIKOR method to identify the most significant ones. Top ten risks which were identified in that study are shown in Table 1. These risks formed the basis of this research.

In this study, underlying facts of top ten risks are examined deeply and explained as follows:

R1) Unnecessary length in the clauses, sentences, and words: Construction contracts are mostly voluminous and complex documents. They contain a significant number of provisions with long sentences that nobody in the project could read with full attention, failing to comprehend project requirements [24]. It was addressed that putting accurate punctuation in long sentences could make the document easier to read [38]. The Flesch Reading Ease Score (FRES), which is one of the most widely used readability formula, considers two variables to estimate readability of documents as; average length of sentences and average number of syllabus per word [15]. Therefore, length in the clauses and sentences, and the number of words in construction contracts need to be minimized adequately to expedite reading and enable clear understanding. When construction contracts are drafted with long clauses, sentences and unnecessary words, then they are hardly read and understood by contractors during contract drafting process.

Table 1 - Most significant readability risks ([25]).

\begin{tabular}{|c|c|c|}
\hline ID & Readability risks & References \\
\hline $\mathrm{R} 1$ & Unnecessary length in the clauses, sentences and words & $\begin{array}{l}\text { Ameer Ali and Wilkinson [35], Besaiso et al [2], } \\
\text { Broome and Hayes [29] }\end{array}$ \\
\hline $\mathrm{R} 2$ & $\begin{array}{l}\text { Unnecessary complexity in the scope of work with } \\
\text { complex noun phrases and improper use of referents }\end{array}$ & $\begin{array}{l}\text { Chong and Oon [36], Rameezdeen and Rajapakse } \\
{[15]}\end{array}$ \\
\hline $\mathrm{R} 3$ & Repetition of words and provisions & $\begin{array}{l}\text { Ameer Ali and Wilkinson [35], Broome and Hayes } \\
\text { [29], Chong and Oon [36] }\end{array}$ \\
\hline $\mathrm{R} 4$ & Use of negative style of language & $\begin{array}{c}\text { Besaiso et al [2], Chong and Zin [1], Menches and } \\
\text { Dorn [37] }\end{array}$ \\
\hline R5 & $\begin{array}{l}\text { Controversial uses to legal terms and incoherence } \\
\text { including other contracts in the projects }\end{array}$ & $\begin{array}{l}\text { Chong and Zin [1], Murphy et al. [20], } \\
\text { Rameezdeen and Rajapakse [15] }\end{array}$ \\
\hline R6 & $\begin{array}{l}\text { Abstractness and ambiguity in word or sentence } \\
\text { causing more than one meaning }\end{array}$ & $\begin{array}{c}\text { Ameer Ali and Wilkinson [35], Besaiso et al [2], } \\
\text { Broome and Hayes [29] }\end{array}$ \\
\hline R7 & $\begin{array}{l}\text { Use of specialised vocabulary, legal terms and legal } \\
\text { jargon }\end{array}$ & $\begin{array}{c}\text { Rameezdeen and Rajapakse [15], Rameezdeen and } \\
\text { Rodrigo [22], Broome and Hayes [29] }\end{array}$ \\
\hline $\mathrm{R} 8$ & Lack of visual representations & Schuhmann and Eichhorn [24] \\
\hline R9 & $\begin{array}{l}\text { Poor grammar use including missing nouns, words } \\
\text { formation }\end{array}$ & Ameer Ali and Wilkinson [35], Chong and Zin [1] \\
\hline $\mathrm{R} 10$ & Unnecessary use of abbreviations & Murphy et al. [20], Beaumont [19] \\
\hline
\end{tabular}


R2) Unnecessary complexity in the scope of work with complex noun phrases and improper use of referents: Construction contracts may contain complex and lengthy work descriptions including the scope of the work, responsible entities, the way requirements are handled etc., which could cause disagreements resulting with conflicts due to improper expressions. Scope of the intended works can be explicitly described without complex noun phrases and improper use of referents. Using verbs instead of noun phrases are recommended to increase the readability of construction contracts [1], [39]. Besides, using "he" or "she" could increase the complexity of the works since they can be used to indicate project manager, engineer or foreman [40]. This risk factor can also be associated with use of double negative phrases and "shall" [36]. For instance, Ameer Ali [41] highlighted the use of "shall" with reference to Malaysian Government design \& build construction contract (Clause 42.1). "... the Contractor shall (meaning: must) pay the Government a sum calculated at the rate ... such damages shall (meaning: may) be recoverable from the ...". Additionally, the following sentence can be given as an example of a complexity of noun phrase "the Government shall in no circumstances be liable to..." [9].

R3) Repetition of words and provisions: This refers to the repetition of any information that has already been provided in other parts of the contracts. It was included in this study since particularly legalese language, with which construction contracts are heavily drafted, is criticized for being complicated and repetitive [42]. It also covers repetition of words with the same meaning to clarify contract documents [36], which is common in legal jargon. (e.g. "claim by any and every..." [9])

R4) Use of negative style of language: Contract clauses that contain negative language and expressions are usually associated with negative emotional reactions to the clauses [37]. The adopted way of expressions in contracts affect the readability of contracts, particularly emotional reactions during reading. Negative language in construction contracts could reduce trust and collaboration among parties [37], [43], which could increase the possibility of conflicts. The following clause component can be given as an example of negative style of language: "... shall not be removed except for use upon the Works, unless the S.O. has consented..." [1].

R5) Controversial uses to legal terms and incoherence including other contracts in the projects: This refers to all incoherent uses with respect to legal terms, other clauses in the contract and other contracts in the projects. Controversial expressions make it hard to interpret the actual meanings and intentions of the provisions [1], [36], [44]. This could result in opportunistic behaviors by contracting parties when things go wrong, thus conflicts. Resolution procedures of conflicts and disputes could be tedious in case of incoherence. When additional clauses or provisions are added, inconsistencies and mistakes need to be avoided to prevent further conflicts [20]. It was addressed that inconsistencies between modifications were one of the top causes of construction disputes in Australia [22].

R6) Abstractness and ambiguity in word or sentence causing more than one meaning: Contract ambiguity can be considered as one of the primary causes of conflicts and claims in construction projects [45]. A contract can be regarded as incomplete based on several factors such as ambiguity, deficiency, inconsistency and defectiveness [11]. Ambiguity can also contribute to possible opportunistic behaviors, thus leading 
disagreement between parties. This factor includes words having double meanings by their nature and expressions such as "meaningful" or "reasonable", and considered in this study since their interpretations may differ based on parties with their incompatible interest [4], [46], [47]. In this context, "inclement weather" can be another example of ambiguous words [9]. When there is high ambiguity in construction contracts, then its readability can be regarded as low.

R7) Use of specialized vocabulary, legal terms and legal jargon: Presence of legalese language can be considered as one of the main causes of clarity and readability issues in construction contracts [22]. This factor refers to the use of too many legal terms and phrases, vocabulary deemed to legal jargon, making the contract difficult to read and understand [1]. It was addressed that minimizing legalese with plain language structure could increase the transparency of contracts [24]. In addition, FIDIC conditions have been criticized for containing many unnecessary legal expressions [2], [29]. It was addressed that drafters of NEC have taken a revolutionary step by abandoning legal language [2].

R8) Lack of visual representations: Visual representation of the contracts can increase the transparency of construction contracts, ensuring that the contracts are handled by project managers adequately [24]. It also includes inadequate presentation of technical documents, implementation details and work visualization that could reduce the clarity of the intended work and increase unwillingness of the employers to read the contracts.

R9) Poor grammar use including missing nouns, words formation: Missing nouns, complex words formation and poor grammar use can be related to clarity problems in construction contracts [1] eventually affecting its readability. For instance, NEC was regarded to promote clarity and simplicity within the contract, however, some researchers asserted that while decreasing the number of words in sentences, it failed to propose good grammar use with missing nouns [19], [20].

R10) Unnecessary use of abbreviations: Abbreviations are naturally used to prevent lengthy sentences and contexts. However, too many abbreviations in a single sentence, provision or clause can reduce their readability. Using abbreviations more than necessary in contracts can be pertained to poor grammatical structure of documents [19].

The following clause can be given as an example of a poorly drafted contract clause in several ways [41]: "This Contract shall be deemed to be a Malaysian Contract and shall accordingly be construed according to the laws for the time being in force in Malaysia and the Malaysian Courts shall have exclusive jurisdiction to hear and determine all actions and proceedings arising out of this Contract and the Contractor hereby submits to the jurisdiction of the Malaysian Courts for the purposes of any such actions and proceedings." First, the sentence is too long (69 words, threefold of what has been suggested by Chong and Zin [1]), legalese and redundant [41]. In addition, the meaning of "Malaysian Contract" is not clear (whether it means that the contract is formed in Malaysia or based on Malaysian law). Separation of "hear" and "determine", and "actions" and "proceedings" could also be considered as clearer. Besides, the role of employer in jurisdiction is also not clear, such that only contractor is referred. For more detailed criticism of this clause (and many others), one may refer to the study of Ameer Ali [41]. 


\section{RESEARCH METHODOLOGY}

The main objective of this study is to reveal causal relationships of readability risks leading conflicts by determining their root causes in construction projects. Analysis of these relationships is important since in most cases, risks are found with inextricable cause-effect interrelations and identification of the most significant readability risks may not always be sufficient for proper risk management. Their cause-effect interrelations can exist in varying extents that may impose further elaboration. For instance, when shortening the long sentences as an improvement in the readability of a contract, the document can become poor in grammar with missing nouns and too many abbreviations, as NEC standard contract is criticized in this respect by some scholars [19], [20]. On the other hand, addition of redundant technical information that could be included in technical specifications would increase the length of the sentences, provisions and clauses. Such examples of cause-effect relationships need to be analyzed, which actually establish the major aim of this study. The research steps and adopted methods to analyze the causal relationships of the most significant readability risks are shown in Fig. 2.

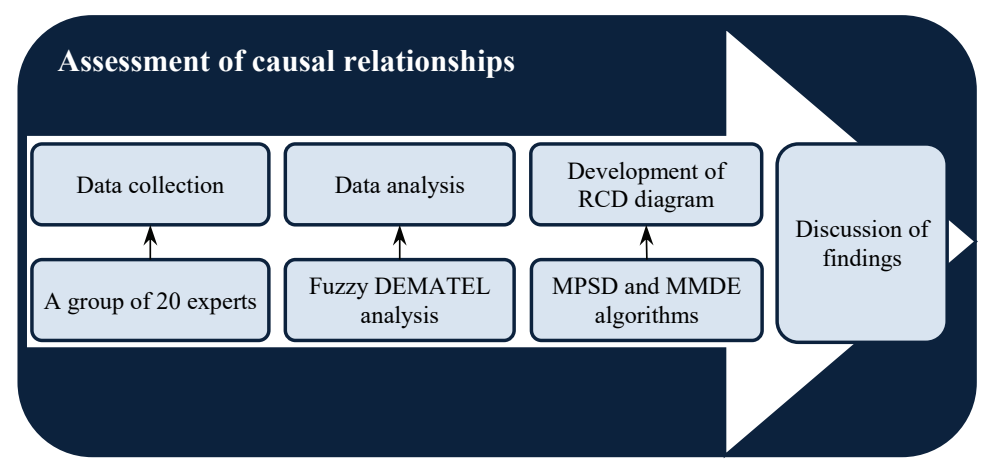

Fig. 2 - Research flow.

The first step of the assessment of causal relationships was to collect data in order to identify root causes of the most significant readability risks. A total number of 20 experts contributed to this study. Their professional backgrounds can be seen in Table 2. Past literature supports the sample sizes used in this study in terms of fuzzy DEMATEL method [48]-[50], since the quality of the data is regarded highly essential in a qualitative research as originally aimed in this study [48], [51]. In the data collection step, a decision framework was formed based on 10 readability risks (Table 1 ) leading to $10 \times 10$ decision matrix. Then, respondents were asked to provide their judgments using the linguistic variables (Table 3 ) regarding the influences of readability risks on each other. In other words, the influence of each readability risk on the others were inquired leading to 90 decisions $(10 \times 9)$ of each expert. 
Table 2 - Professional background of experts.

\begin{tabular}{|c|c|c|c|c|c|c|c|}
\hline ID & Proficiency & $\begin{array}{c}\text { Education } \\
\text { level }\end{array}$ & Role & Organization & $\begin{array}{l}\text { Experience in } \\
\text { construction } \\
\text { industry } \\
\text { (Year) }\end{array}$ & $\begin{array}{l}\text { Experience in } \\
\text { contract } \\
\text { administration } \\
\text { (Year) }\end{array}$ & $\begin{array}{c}\text { Budget } \\
\text { responsible (USD } \\
\$)\end{array}$ \\
\hline E1 & Civil engineering & Bachelor & Owner & Subcontractor & 21 & 16 & $1-10$ Million \\
\hline $\mathrm{E} 2$ & Civil engineering & MSc & Director & Contractor & 24 & 12 & $1-10$ Million \\
\hline E3 & Civil engineering & $\mathrm{PhD}$ & Senior executive director & Client & 22 & 16 & $10-100$ Million \\
\hline E4 & Civil engineering & Bachelor & Senior executive director & Client & 25 & 17 & $10-100$ Million \\
\hline E5 & Civil engineering & Bachelor & Owner & Contractor & 32 & 27 & $\geq 100$ Million \\
\hline E6 & Civil engineering & Bachelor & General manager & Client & 17 & 13 & $\geq 100$ Million \\
\hline E7 & Civil engineering & Bachelor & Project manager & Client & 27 & 23 & $1-10$ Million \\
\hline E8 & Civil engineering & Bachelor & Vice general director & Client & 21 & 18 & $10-100$ Million \\
\hline E9 & Civil engineering & Bachelor & Contract manager & Contractor & 29 & 22 & $1-10$ Million \\
\hline E10 & Architecture & MSc & Technical office architect & Contractor & 7 & 4 & $\leq 1$ Million \\
\hline E11 & Civil engineering & Bachelor & Senior executive director & Client & 32 & 21 & $\geq 100$ Million \\
\hline E12 & Civil engineering & Bachelor & Project coordinator & Contractor & 20 & 13 & $10-100$ Million \\
\hline E13 & Civil engineering & Bachelor & Site engineer & Subcontractor & 5 & 5 & $\leq 1$ Million \\
\hline E14 & Architecture & Bachelor & General manager & Client & 24 & 20 & $1-10$ Million \\
\hline E15 & Civil engineering & $\mathrm{PhD}$ & Contract manager & Contractor & 21 & 21 & $1-10$ Million \\
\hline E16 & Architecture & Bachelor & Project manager & Client & 14 & 11 & $10-100$ Million \\
\hline E17 & Architecture & $\mathrm{MSc}$ & Technical office manager & Client & 11 & 8 & $1-10$ Million \\
\hline E18 & Architecture & MSc & Design manager & Client & 13 & 10 & $1-10$ Million \\
\hline E19 & Architecture & Bachelor & Project coordinator & Client & 28 & 20 & $10-100$ Million \\
\hline E20 & Civil engineering & Bachelor & Technical office engineer & Client & 8 & 6 & $1-10$ Million \\
\hline
\end{tabular}

Table 3 - Fuzzy linguistic scales used in fuzzy DEMATEL method.

\begin{tabular}{lll}
\hline Linguistic variables & Influence score & Triangular fuzzy numbers \\
\hline No influence & 0 & $(0.00,0.00,0.25)$ \\
Very low influence & 1 & $(0.00,0.25,0.50)$ \\
Low influence & 2 & $(0.25,0.50,0.75)$ \\
High influence & 3 & $(0.50,0.75,1.00)$ \\
Very high influence & 4 & $(0.75,1.00,1.00)$ \\
\hline
\end{tabular}

The collected data was analyzed by a multi-criteria decision-making method, fuzzy DEMATEL. DEMATEL was selected particularly for its wide application as a practical method to underly root causes of various problems in the literature [52] such as labor productivity [53], intersection safety [54], waste management [55], and project performance [56]. This method has been used by many researchers, since it is powerful in separating net causes from net effects ensuring the underlying causes of the problems [54], drawing a root cause degree (RCD) diagram and aiding the development of countermeasures to the specific issues [57]. DEMATEL approach is very useful when critical and suitable 
decisions for specific problems are sought [58], [59]. In addition, a network relation map can be constructed, which enables the observations of the correlated factors [60]. The method has been regarded as one of the most prominent methods to evaluate the importance of causal relationships among included criteria as well as having an ability to validate the interrelationships of evaluated criteria [48]. Since traditional DEMATEL method considers neither fuzziness, nor subjectivity in decision-making processes, fuzzy DEMATEL approach was adopted. Respondents, who participated in the questionnaire were chosen by judgment sampling based on their experiences and roles in construction contract administration [61]. At this point, a variety of participant features were considered to mark diversification in contract administration with respect to backgrounds of the participants. Interviews were performed through face-to-face individual discussion sessions. The objective of the research and fundamentals of DEMATEL analysis were explained to maximize the accuracy in their judgments for better representation.

For the initial step of the fuzzy DEMATEL method, direct relation matrix (T) was formed by experts through adopting pairwise comparisons between readability risks. Each element in $\mathrm{T}$ was converted to triangular fuzzy number (TFN) denoted as $\left(l_{i j}, m_{i j}, r_{i j}\right)$ indicating the influences of risk $i$ on risk $j$. Triangular fuzzy scale used in fuzzy DEMATEL method is presented in Table 3 [62].

Adopted fuzzy DEMATEL method included five main steps as follows [62]:

1) TFNs were converted into direct relation matrix $(Z)$. For this preliminary step, normalization was performed by using Eqs. (1) - (3).

$$
\begin{aligned}
& x r_{i j}^{n}=\frac{\left(r_{i j}^{n}-\min l_{i j}^{n}\right)}{\Delta_{\min }^{\max }} \\
& x m_{i j}^{n}=\frac{\left(m_{i j}^{n}-\min l_{i j}^{n}\right)}{\Delta_{\min }^{\max }} \\
& x l_{i j}^{n}=\frac{\left(l_{i j}^{n}-\min l_{i j}^{n}\right)}{\Delta_{\min }^{\max }}
\end{aligned}
$$

where $\Delta_{\min }^{\max }=\max r_{i j}^{n}-\min l_{i j}^{n} ; n=1,2,3, \ldots, h$ is the number of experts. Then, right $(r s)$ and left $(l s)$ normalized values were calculated as follows:

$$
\begin{aligned}
x r s_{i j}^{n} & =\frac{x r_{i j}^{n}}{\left(1+x r_{i j}^{n}-x m_{i j}^{n}\right)} \\
x l s_{i j}^{n} & =\frac{x m_{i j}^{n}}{\left(1+x m_{i j}^{n}-x l_{i j}^{n}\right)}
\end{aligned}
$$

Then, aggregated crisp values were calculated by using Eqs. (6) - (8).

$x_{i j}^{n}=\frac{x l s_{i j}^{n}\left(1-x l s_{i j}^{n}\right)+x r s_{i j}^{n} \times x r s_{i j}^{n}}{\left(1-x l s_{i j}^{n}+x r s_{i j}^{n}\right)}$ 
$Z_{i j}^{n}=\min l_{i j}^{n}+x_{i j}^{n} \times \Delta_{\min }^{\max }$

$Z_{i j}=\frac{\left(Z_{i j}^{1}+Z_{i j}^{2}+\cdots+Z_{i j}^{h}\right)}{h}$

where $x_{i j}^{n}$ is the total normalized crisp values; $Z_{i j}^{n}$ is the computed crisp value for expert $n$.

2) Generalized direct relation matrix (S) was calculated by Eq. (9).

$\mathrm{S}=\frac{1}{\max _{1 \leq i \leq n} \sum_{j=1}^{n} Z_{i j}} \times \mathrm{Z}$

3) Total relation matrix (M) was computed by using Eq. (10) as follows:

$\mathrm{M}=\mathrm{S}(\mathrm{I}-\mathrm{S})^{-1}$

where, I is the identity matrix. Therefore, indirect effects of readability risks on each other were taken into account. The overall total relation matrix of readability risks is presented in Table 4.

Table 4 - Total relation matrix.

\begin{tabular}{lcccccccccc}
\hline $\mathrm{R}$ & $\mathrm{R} 1$ & $\mathrm{R} 2$ & $\mathrm{R} 3$ & $\mathrm{R} 4$ & $\mathrm{R} 5$ & $\mathrm{R} 6$ & $\mathrm{R} 7$ & $\mathrm{R} 8$ & $\mathrm{R} 9$ & $\mathrm{R} 10$ \\
\hline $\mathrm{R} 1$ & 0.78 & 0.92 & 0.85 & 0.85 & 0.93 & 0.90 & 0.78 & 0.62 & 0.81 & 0.72 \\
$\mathrm{R} 2$ & 0.94 & 0.87 & 0.90 & 0.91 & $\mathbf{0 . 9 9}$ & $\mathbf{0 . 9 7}$ & 0.82 & 0.66 & 0.88 & 0.78 \\
$\mathrm{R} 3$ & 0.89 & 0.93 & 0.79 & 0.89 & $\underline{0.95}$ & 0.93 & 0.79 & 0.64 & 0.84 & 0.75 \\
$\mathrm{R} 4$ & 0.91 & $\underline{0.96}$ & 0.90 & 0.79 & $\underline{0.95}$ & $\underline{0.96}$ & 0.79 & 0.64 & 0.85 & 0.76 \\
$\mathrm{R} 5$ & 0.94 & $\mathbf{1 . 0 0}$ & 0.93 & 0.91 & 0.89 & $\mathbf{0 . 9 9}$ & 0.83 & 0.67 & 0.88 & 0.78 \\
$\mathrm{R} 6$ & $\underline{0.95}$ & $\mathbf{1 . 0 0}$ & 0.94 & 0.94 & $\mathbf{1 . 0 0}$ & 0.89 & 0.84 & 0.68 & 0.90 & 0.81 \\
$\mathrm{R} 7$ & 0.86 & 0.91 & 0.85 & 0.85 & 0.91 & 0.90 & 0.68 & 0.62 & 0.80 & 0.71 \\
$\mathrm{R} 8$ & 0.69 & 0.70 & 0.67 & 0.67 & 0.73 & 0.70 & 0.59 & 0.43 & 0.62 & 0.56 \\
$\mathrm{R} 9$ & $\mathbf{0 . 9 6}$ & $\mathbf{1 . 0 0}$ & $\mathbf{0 . 9 6}$ & $\underline{0.95}$ & $\mathbf{1 . 0 1}$ & $\mathbf{1 . 0 1}$ & 0.84 & 0.67 & 0.80 & 0.79 \\
$\mathrm{R} 10$ & 0.72 & 0.75 & 0.70 & 0.70 & 0.76 & 0.75 & 0.63 & 0.51 & 0.67 & 0.53 \\
\hline
\end{tabular}

Note: Bold values are equal or higher than the MMDE, and underlined values are equal or higher than the MPSD thresholds.

In Table 4, the sum of rows and the sum of columns were then referred as D and R, respectively. $\mathrm{D}+\mathrm{R}$ was denoted as the prominence $\left(P_{i}\right)$, while $\mathrm{D}-\mathrm{R}$ was the net effect $\left(E_{i}\right)$. Prominence and net effects of readability risks are presented in Table 5. It is important to note that positive $\mathrm{E}$ value indicates that the corresponding risk is a net cause factor (influences others more than it is influenced by), while a negative E value indicates that the risk is a net effect factor (influenced by others more than it influences others). 
Table 5 - Prominence and net effect.

\begin{tabular}{lcccc}
\hline $\mathrm{ID}$ & $\mathrm{D}$ & $\mathrm{R}$ & $E_{i}$ & $P_{i}$ \\
\hline $\mathrm{R} 1$ & 8.14 & 8.64 & -0.50 & 16.78 \\
$\mathrm{R} 2$ & 8.72 & 9.05 & -0.33 & 17.77 \\
$\mathrm{R} 3$ & 8.40 & 8.49 & -0.09 & 16.89 \\
$\mathrm{R} 4$ & 8.50 & 8.46 & 0.04 & 16.96 \\
$\mathrm{R} 5$ & 8.82 & 9.13 & -0.31 & 17.96 \\
$\mathrm{R} 6$ & 8.95 & 9.02 & -0.07 & 17.97 \\
$\mathrm{R} 7$ & 8.09 & 7.58 & 0.51 & 15.68 \\
$\mathrm{R} 8$ & 6.39 & 6.14 & 0.24 & 12.53 \\
$\mathrm{R} 9$ & 9.01 & 8.05 & 0.95 & 17.06 \\
$\mathrm{R} 10$ & 6.74 & 7.19 & -0.44 & 13.93 \\
\hline
\end{tabular}

4) Since all readability risks have effects on others in a varying extent, an acceptable threshold value must be established to keep the complexity of the identified system manageable, so that the ones with smaller impacts in total relation matrix can be filtered out. It should be noted that only an acceptable degree of threshold value can provide meaningful information about the relation system [63]. Therefore, threshold values should be neither very high, nor very low. Two different approaches were addressed in the literature for threshold value determination as mean plus standard deviation (MPSD) approach and maximum mean de-entropy (MMDE) algorithm. In this study both threshold values were calculated.

Average and standard deviation of all elements in Table 4 were calculated in MPSD approach and their sum was set as a threshold value. 0.946 was computed as a threshold value by adopting MPSD approach through Eq. (11).

$T^{M P S D}=S D+\bar{x}$

where $S D$ and $\bar{x}$ are the standard deviation and average values of all 100 elements in Table 4, and $T^{M P S D}$ is the threshold value calculated by adopting MPSD approach.

As an alternative approach, the threshold value was also determined based on robust MMDE algorithm based on entropy approach proposed by Li and Tzeng [63]. This algorithm has been implemented in information science, in which entropy refers to the criterion used to determine the amount of uncertainty. MMDE algorithm used in fuzzy DEMATEL analysis involved the following steps [48], [63]-[65]:

(i) Matrix $\mathrm{M}$ in Table 4 was converted to an ordered set $M$, which involves $\left\{m_{11}, m_{12}, \ldots, m_{21}, m_{22}, \ldots, m_{n n}\right\}$ where $m_{n n}$ is an element of $n \times n$ total relation matrix. Then, each element in the matrix was rearranged from the highest to the smallest and converted into a $M^{*}$ denoting an ordered triplet as $\left(m_{i j}, x_{i}, x_{j}\right)$. In this triplet, $m_{i j}$ is the influence value computed in the matrix $\mathrm{M}, x_{i}$ and $x_{j}$ are the order of row and column numbers referred as dispatch 
node and receive node, respectively. For simplification reasons, only dispatch node was considered in the steps (ii)-(iv).

(ii) The second element of $M^{*}$ was obtained for each element of the total relation matrix, to generate new set of ordered dispatch node, $M^{D i}$ as $\left(x_{1}, x_{2}, \ldots, x_{n}\right)$ with a corresponding probability of $P=\left(p_{1}, p_{2}, \ldots, p_{n}\right)$.

(iii) The first element of $M^{D i}$ was taken as a new set $M_{t}^{D i}$ to assign the probability of each element in the new set. Accordingly, $H_{D}$ of the set $M_{t}^{D i}, H_{t}^{D i}$ was computed by using Eq. (12).

$$
\begin{aligned}
& H\left(p_{1}, p_{2}, \ldots, p_{n}\right)=-\sum p_{i} \cdot \ln \left(p_{i}\right) \\
& p_{i}=\frac{k}{m}
\end{aligned}
$$

Subject to:

$\sum_{i=1}^{n} p_{i}=1$

$p_{i} \cdot \ln \left(p_{i}\right)=0 \quad$ if $p_{i}=0$

$H^{D}=H\left(\frac{1}{n}, \frac{1}{n}, \ldots, \frac{1}{n}\right)-H\left(p_{1}, p_{2}, \ldots, p_{n}\right)$

where $p_{i}$ is the probability of the variable $x_{i}, m$ is the number of variables in $M^{D i}, k$ is the observed frequency of variable $x_{i}$, and $H^{D}$ is the de-entropy value.

(iv) The mean de-entropy was determined by using Eq. (17) as follows:

$$
M D E_{t}^{D i}=\frac{H_{t}^{D i}}{N\left(M_{t}^{D i}\right)}
$$

where $N\left(M_{t}^{D i}\right)$ is the number of variables with unique values. Maximum $M D E_{t}^{D i}$ and its corresponding $M_{t}^{D i}$ values were then chosen in a number of $C\left(M_{t}^{D i}\right)$ mean de-entropy values, where $C\left(M_{t}^{D i}\right)$ is the total number of variables. This dispatch node set was denoted as $M_{\text {max }}^{D i}$.

(v) An ordered receive node set $M^{R e}$ and a MMDE set $M_{\max }^{R e}$ was computed by adopting the same steps (ii)-(iv).

(vi) First $u$ elements in $M^{*}$ was taken as the subset while having $T^{T h}$, which consists of $M_{\max }^{D i}$ and $M_{\max }^{R e}$, the threshold value was determined from the minimum influence value in $T^{T h}$. After all the calculations made in Excel, MMDE value was calculated as 0.964 .

Hence, threshold values calculated through MMDE (0.964) and MPSD (0.946) algorithms were used to highlight significant relationships between readability risks and indicated in Table 4 (with bolded and underlined values, respectively). It is important to 
note the difference between significant relationships calculated through MMDE and MPSD algorithms. The relationships between readability risks were stronger regarding threshold value calculated through MMDE algorithm compared to one attained via MPSD method. In this study, both MMDE and MPSD threshold values were used to draw attention to the causal risks, while other researchers might consider relationships based on only MMDE method to focus on the more crucial causal relationships.

5) At the last step of fuzzy DEMATEL analysis, root cause degree (RCD) diagram was drawn by mapping the dataset of $(\mathrm{D}+\mathrm{R}, \mathrm{D}-\mathrm{R})$, where $(\mathrm{D}+\mathrm{R})$ was put at horizontal axis, and $(\mathrm{D}-\mathrm{R})$ was put at vertical axis. If $\left(D_{x}-R_{x}\right)>0$, then the criterion $x$ dispatches the impact on other factors more than it receives [66]. RCD diagram of readability risks is illustrated in Fig. 3. Calculated threshold values from both MPSD and MMDE approaches were used in the diagram to show the relationships between readability risks. RCD diagram (Fig. 3) drawn based on total relation matrix (Table 4) and threshold values shows that R9, R7, R8 and R4 were the cause factors (influences other risks more than influenced by others), while the rest of the readability risks were effect factors (affected by the factors rather than affecting the others). R9 was the most significant causal factor influencing majority of the readability risks apart from R7, R8 and R10, which were found to be independent readability risks. On the other hand, R1 was the most affected readability risk in the overall scheme, which was directly influenced by $\mathrm{R} 9$ (with respect to MMDE) and R6 (with respect to MPSD).

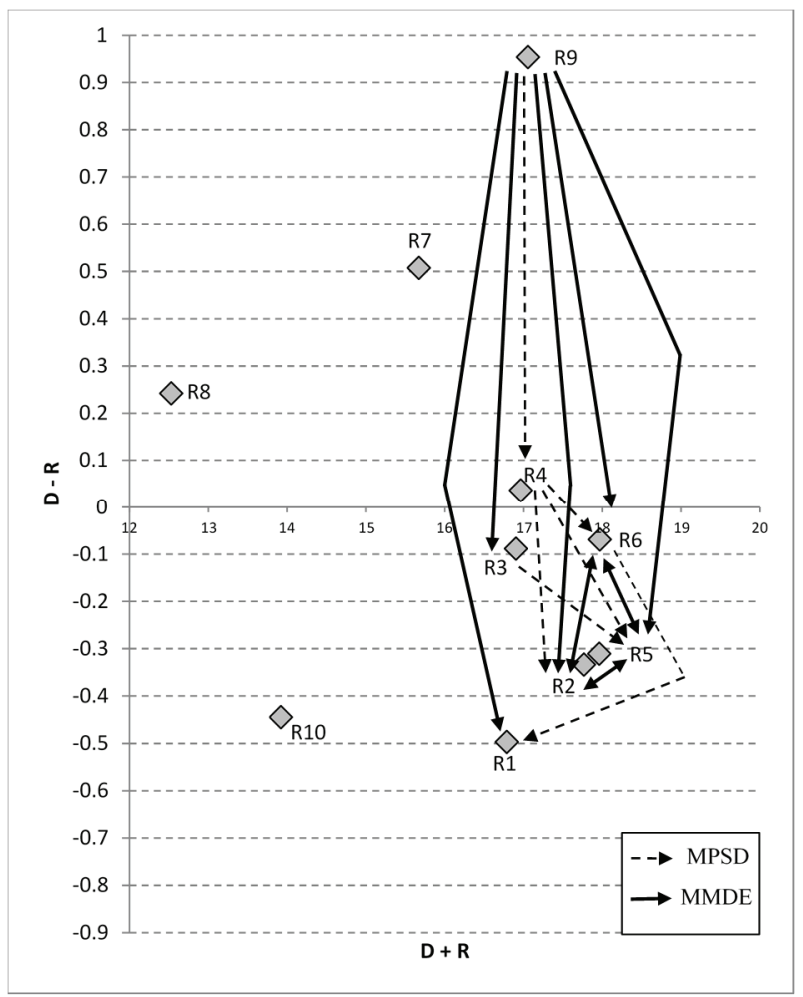

Fig. 3 - RCD diagram of readability risks. 


\section{DISCUSSIONS}

Based on analysis results of Koc and Gurgun [25], the top five most significant readability risks were identified as "unnecessary complexity in the scope of work with complex noun phrases and improper use of referents (R2)", "abstractness and ambiguity in word or sentence causing more than one meaning (R6)", "unnecessary length in the clauses, sentences, and words (R1)", "lack of visual representations (R8)", and "controversial uses to legal terms and incoherence including other contracts in the projects (R5)". These findings may be of interest for decision makers and contract drafters during contract preparation and administration phases. With a closer look into the analysis of their causal relationships, further details and outcomes could be provided to understand their impacts on each other, which is actually the aim of this study. Findings of fuzzy DEMATEL were helpful to map out the root cause factors within the most significant risks based on their causal relationships. For example, "poor grammar use including missing nouns, words formation (R9)" and "use of specialized vocabulary, legal terms and legal jargon (R7)" were found to be the root causes of readability risks in construction contracts, with 0.95 and 0.51 net effect values, respectively. Other two cause factors (R8 and R4) were assessed with net effect values less than 0.25 , separating top two from them. It can be noted that the results of prioritization solely may not always be adequate to develop effective measures, since improvements regarding them may not clarify the contract document as expected due to lack of understanding the causal relationships between them. Table 6 shows the most significant ten readability risks and their roles in causal hierarchy developed by using fuzzy DEMATEL approach.

Table 6 - The role of the most significant ten readability risks in causal hierarchy.

\begin{tabular}{lccccc}
\hline $\begin{array}{l}\text { Risk } \\
\text { factor }\end{array}$ & $\begin{array}{c}\text { Rank in fuzzy VIKOR } \\
\text { Koc and Gurgun, [25] }\end{array}$ & $\begin{array}{c}\text { Causal rank in Fuzzy } \\
\text { DEMATEL }\end{array}$ & $\begin{array}{c}\text { Causal } \\
\text { position }\end{array}$ & Influence on & Influenced by \\
\hline R2 & 1 & 8 & Net effect & R5, R6 & R4, R5, R6, R9 \\
R6 & 2 & 5 & Net effect & R1, R2, R5 & R2, R4, R5, R9 \\
R1 & 3 & 10 & Net effect & - & R6, R9 \\
R8 & 4 & 3 & Net cause & - & - \\
R5 & 5 & 7 & Net effect & R2, R6 & R2, R3, R4, R6, R9 \\
R9 & 6 & 1 & Net cause & R1, R2, R3, R4, R5, R6 & - \\
R7 & 7 & 2 & Net cause & - & - \\
R4 & 8 & 4 & Net cause & R2, R5, R6 & R9 \\
R3 & 9 & 6 & Net effect & R5 & - \\
R10 & 10 & 9 & Net effect & - & R9 \\
\hline
\end{tabular}

Some additional highlights can be pointed out based on analysis findings. One of the most remarkable outcomes was that four of the top five readability risks, which were highlighted by Koc and Gurgun [25], were actually found to be net effect factors. The results may be of particular importance, since in fact improvements in effect factors may not be effective as much as expected, allowing related problems remain in the contract documents if 
underlying causes are disregarded. For instance, despite reducing the length of the sentences could be regarded as one of the mostly recommended measures, this could lead poor grammatical structure with missing nouns [20], which was found to be the most significant causal factor in this study. A clear flow from R9 to R1 was found in this study (Fig. 3), which is on the contrary to what is generally believed [20]. The reason of this could be that poor grammatical structure and missing nouns could cause potential readers of construction contracts to perceive the sentences are unnecessarily long complicating its readability. That is probably why reducing sentence length was ineffective in facilitating the readability of sentences due to issues caused by poor grammatical structure [20]. As another example, excessive use of legal terminology could make contracts even harder to read since they are drafted by lawyers but used by engineers. It can be noted that abandoning legal terminology has been regarded as one of the revolutionary steps of NEC drafters [2], and use of specialized vocabulary, legal terms and legal jargon (R7) was found to be the second causal readability risk in this study. Five of the six net effect factors in Table 6 were influenced by "poor grammar use including missing nouns, words formation (R9)", making it the most significant causal factor affecting readability of construction contracts. In other words, even though problems about noun phrases, referents, ambiguous words and controversies could contribute to the poor contract document at most; using wrong grammatical structure with missing nouns and poor word formations could be the root causes of these problems. Fig 3. shows clear flows from R9 at the top, to the net effects in the middle and at the bottom. R7 was determined and shown as the second most significant causal factor in RCD diagram. Although it was not found to be the significant cause of any of the other risks, it was identified to be affecting all the others in some extent, without being influenced by them. One of the experts contributed to this study indicated that sometimes it was very difficult to incorporate the updated standards to contract provisions, thus increasing the readability risk of the corresponding clauses. Frequently updated conditions with legal terminology could decrease the quality and readability of contract documents [21].

According to the threshold values calculated by MPSD and MMDE approaches, "use of specialized vocabulary, legal terms and legal jargon" (R7), "lack of visual representations" (R8), and unnecessary use of abbreviations (R10) were found to be independent readability risks. In other words, when these risks emerged, then the readability of overall contract document was affected, more than due to emergence of other individual risks. Visual representation (R8) with respect to transparency [24], and use of abbreviations (R10) with respect to simplicity [20] were important readability factors, affecting and affected by others below the threshold values. The results are considered pertinent since R8 and R10 cannot easily be associated with other readability risks. Visualization could significantly supplement contract documents through diagrams, charts, timelines, images etc., which may appear inside a contract or alongside of it [67], making it harder to relate with other readability factors. Similarly, excessive use of abbreviation could paralyze the ability of the readers to think clearly [68], as a discriminating attribute of it from others. On the other hand, despite "use of specialized vocabulary, legal terms and legal jargon" (R7) was the second most causal factor in RCD diagram, it was determined as an independent readability risk. The reason of this could be that experts participated to fuzzy DEMATEL questionnaires kept the influences of R7 on the other risks in a large extent but just below the calculated threshold values. At the very bottom of the RCD diagram, "unnecessary 
length in the clauses, sentences and words" (R1) was seen as a net effect factor influenced by "poor grammar use including missing nouns, words formation" (R9), with respect to MMDE and R6 with respect to MPSD. Despite R1 was the third most significant readability risk, amelioration of sentences in terms of length could not be as effective as expected since it was the most affected factor placed at the bottom of the RCD diagram. There were some other readability factors contributing to the length of the sentences, provisions and clauses, relatively less significant but underlying cause factors. Therefore, improvement of the length related risks should not be considered individually to improve the quality of construction contracts [20].

Interestingly, "unnecessary complexity in the scope of work with complex noun phrases and improper use of referents" (R2), "controversial uses to legal terms and incoherence including other contracts in the projects" (R5), "abstractness and ambiguity in word or sentence causing more than one meaning" (R6) triangle emerged with a dyadic nature such that all affected each other (Fig. 3). This can be another significant finding since it indicated that differentiating these three from each other during contract drafting process could be less effective, compared to the risk mitigation measures covering all three risks. The results implied that scope complexity with inadequate noun phrases, ambiguous expressions and words, and incoherence could be regarded as bound to each other in construction contracts. For instance, when the scope of the work is complex by using inadequate noun phrases, then its provisions relationally unclear. Correspondingly, when there are too many ambiguous words in the provisions, then the scope of the work would become more complex. Similar to this, when incoherence with controversial uses is high, then the scope of the work could become more complex. If the complexity of the scope of the work is apparent in different contracts in a project, then it is likely to include inconsistent expressions between other contracts in the project. This highlights that in some cases, considering group of measures could be more effective than treating them individually.

\section{IMPLICATIONS FOR CONTRACT DRAFTERS}

Poor contract documentation was considered by various scholars as major causal factors incurring construction conflicts [69], [70]. With the aim of increasing the ease of contract reading, this study further revealed the underlying causes of readability problems in construction contracts. Ranking the most significant readability risks could provide contract drafters a guideline for risk management; however, solely focusing on this might cause overlooking the fact that risk factors affecting readability of construction contracts are related to each other. With the butterfly effect in mind [71], estimating the consequences of any positive steps on the other readability risks is essential for improved contract drafting process. By managing underlying causes determined through fuzzy DEMATEL analysis [72], sub-optimality in the readability of construction contracts can be improved in a more effective manner, differentiating cause factors from effect factors.

While drafting contract and performing modifications, it can be difficult for contract drafters to consider the impacts of the modifications on the clarity and readability of documents [22]. Traditionally, reducing the number of syllables in words, words in sentences, and sentences in clauses are recommended [1], which are also considered in readability formulas [73], and adopted commonly by contract drafters to increase clarity 
and ease of reading. This can be related to the fact that construction contracts are usually considered as voluminous documents, with long and complex sentences. However, despite regarded as one of the most significant readability risks, "unnecessary length in the clauses, sentences, and words" was found to be the most affected factor in this study, ranking last in the causal hierarchy. This finding entails particular attention, since it reveals that the efforts made by improving contract documents through length-related measures could be ineffective at some point if other causal risks that result in lengthy documents are not managed properly. Furthermore, "scope complexity with improper noun phrases and referents" was found to be the most significant factor affecting the readability of construction contracts, however, ranked eighth in causal hierarchy based on the fuzzy DEMATEL method outcomes. By looking into RCD diagram, poor grammar use, ambiguous words and sentences, and their incoherent uses should be avoided to reduce complexity of the scope of work. RCD diagram can also be used to develop countermeasures for some of the particular readability problems. Fig. 4 shows a framework for scope drafting in a construction contract developed based on RCD diagram, as a practical implication.

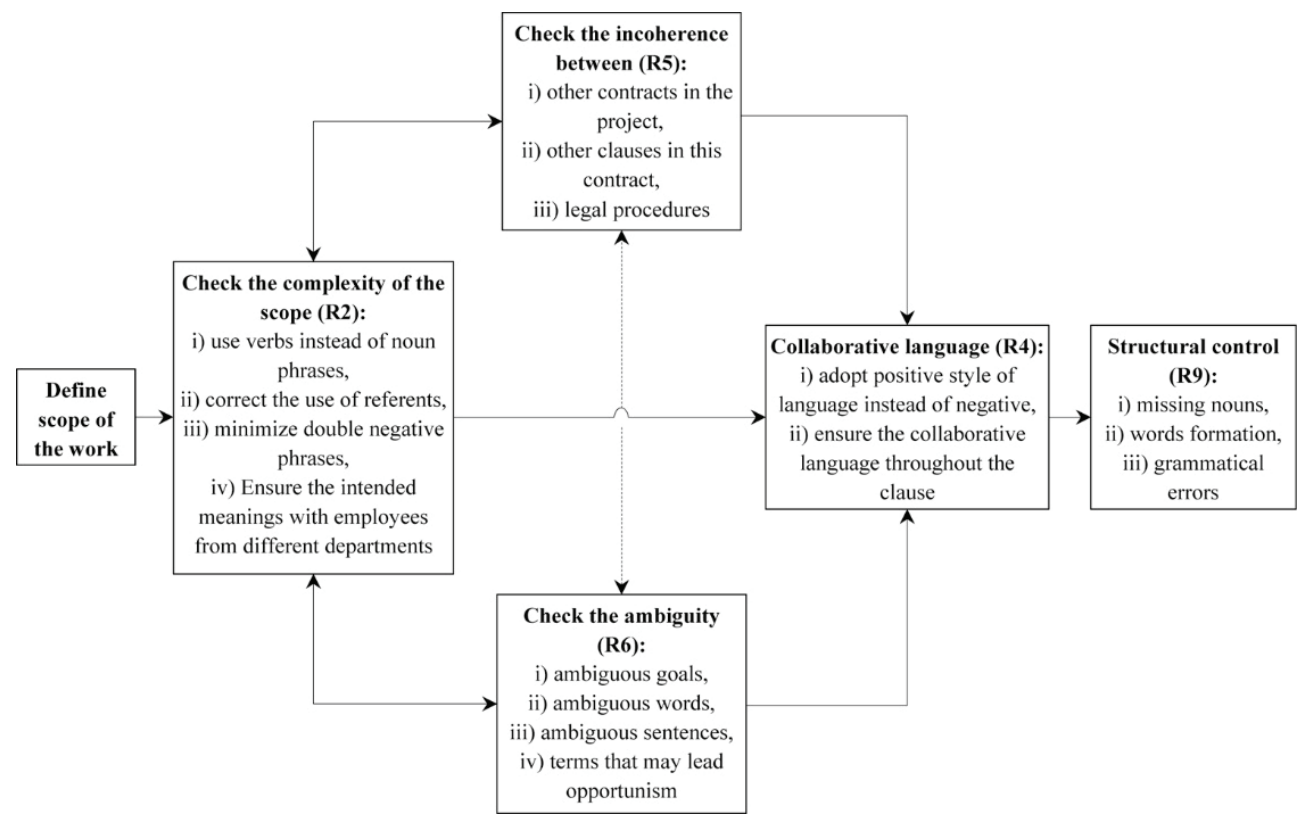

Fig. 4 - Example of a scope drafting based on proposed RCD diagram.

To perform useful improvements in overall contract readability to prevent contractual conflicts, four of the readability risks, which were determined as net causes require proper management. These factors are particularly important for contract drafters since effective measures should be adopted to minimize the negative impacts of the underlying cause factors, solving the readability problems in contracts immediately. These readability risks were identified as: poor grammar use including missing nouns, words formation; use of specialised vocabulary, legal terms and legal jargon; lack of visual representations; and use 
of negative style of language. Therefore, while drafting construction contracts or modifications to standard contract forms, contract drafters should pay more attention to these four risks to increase clarity and readability of documents. Such a preventative approach against potential disputes can be considered as an effective strategy for construction projects since the conflicts between contracting parties can be avoided from emerging during project execution process, with the efforts made during contract drafting process.

\section{CONCLUSION}

This study aimed to reveal underlying root causes of readability risks in contraction contracts. In this context, the most significant readability risks were analyzed by fuzzy DEMATEL method to specify the cause-effect relationships among them. The adoption of fuzzy DEMATEL analysis contributes a lot to obtain the findings in this study since components of contracts have strong relationship with each other. Without focusing on the underlying cause factors, the intended measures could not be as effective as expected.

Some significant highlights can be implied from the findings of fuzzy DEMATEL analysis. First, four of the most significant five risks were found to be net effect factors, indicating the ineffectiveness of the traditionally suggested measures for smooth, readable, and clear contract documentation. "Poor grammar use including missing nouns, words formation" and "use of specialized vocabulary, legal terms and legal jargon" were determined as the most causal factors, while "unnecessary length in the clauses, sentences, and words" and "unnecessary use of abbreviations" were the most affected readability risks. Contract clarification strategies can be employed for proper grammar use, missing nouns, words formation, and specialized legal terms to improve the whole contract documents most effectively. Scope complexity, ambiguity, and incoherence were determined to be as a triangle with dyadic relationships with each other. Therefore, remediation in any of them could improve the conditions of others relationally. This can depict the picture of scope complexity in construction contracts.

The literature lacks the investigation of underlying causes of readability risks in construction contracts. Discovering the root causes of readability risks and developing countermeasures accordingly to improve the readability of construction contracts can establish the fundamentals of successful risk management. Without the proposed approach, the real facts of risks and their underlying causal relationships could be overlooked resulting without substantial benefits from risk management implementation. Therefore, these interrelationships need to be accounted for particularly during contract drafting phase. The root cause degree diagram can be used to develop countermeasures for some particular readability issues. The findings of this study are useful for contract drafters, dealing with traditional, standard contract forms such as FIDIC and NEC, or contract modifications, by emphasizing the most effective measures to improve the quality of contract documents. Modifications to the specific clauses in standard contract forms could be made based on RCD diagram proposed in this study, and the results can be investigated in a case study by interested researchers in the future. 


\section{References}

[1] Chong, H. Y. and Zin, R. M., A case study into the language structure of construction standard form in Malaysia, International Journal of Project Management 28, 6016082010 .

[2] Besaiso, H., Fenn, P., Emsley, M., and Wright, D., A comparison of the suitability of FIDIC and NEC conditions of contract in Palestine: A perspective from the industry, Engineering, Construction and Architectural Management 25, 241-256 2018.

[3] El-Sayegh, S. M. and Mansour, M. H., Risk assessment and allocation in highway construction projects in the UAE, Journal of Management in Engineering 31, 040150042015.

[4] Zhang, L., Fenn, P., and Fu, Y., To insist or to concede? Contractors' behavioural strategies when handling disputed claims, Engineering, Construction and Architectural Management 26, 424-443 2019.

[5] Cheung, S. O. and Yiu, T. W., Are construction disputes inevitable?, IEEE Transactions on Engineering Management 53, 456-470 2006.

[6] Saseendran, A., Bigelow, B. F., Rybkowski, Z. K., and Jourdan, D. E., Disputes in Construction: Evaluation of Contractual Effects of ConsensusDOCS, Journal of Legal Affairs and Dispute Resolution in Engineering and Construction 12, 04520008 2020.

[7] El-Adaway, I. H., Abotaleb, I. S., Eid, M. S., May, S., Netherton, L., and Vest, J., Contract Administration Guidelines for Public Infrastructure Projects in the United States and Saudi Arabia: Comparative Analysis Approach, Journal of Construction Engineering and Management 144, 040180312018.

[8] Love, P. E. D., Davis, P. R., Cheung, S. O., and Irani, Z., Causal discovery and inference of project disputes, IEEE Transactions on Engineering Management 58, 400-4112011.

[9] Chong, H. Y. and Zin, R. M., Construction contract administration- an approach on clarity, Clarity 60, 6-10 2008.

[10] Arcadis, Global Construction Disputes Report: Collaborating to achieve project excellence, Amsterdam, Netherlands, 2020.

[11] Cheung, S. O. and Pang, K. H. Y., Anatomy of construction disputes, Journal of Construction Engineering and Management 139, 15-23 2013.

[12] Maqsoom, A., Wazir, S. J., Choudhry, R. M., Thaheem, M. J., and Zahoor, H., Influence of Perceived Fairness on Contractors' Potential to Dispute: Moderating Effect of Engineering Ethics, Journal of Construction Engineering and Management 146, 040190902020.

[13] Wang, Y., Chen, Y., Wang, W., Chen, Y., and Jin, M., Revisiting the Relationship Between Contract Governance and Contractors' Opportunistic Behavior in Construction Projects, IEEE Transactions on Engineering Management 1, 1-13 2019.

[14] Cevikbas, M. and Koksal, A., An Investigation of Litigation Process in Construction Industry in Turkey, Teknik Dergi 29, 8715-8729 2018. 
[15] Rameezdeen, R. and Rajapakse, C., Contract interpretation: The impact of readability, Construction Management and Economics 25, 729-737 2007.

[16] Gunduz, M. and Elsherbeny, H. A., Operational Framework for Managing Construction-Contract Administration Practitioners ' Perspective through Modified Delphi Method, Journal of Construction Engineering and Management 146, 0401911102020.

[17] Yao, M. et al., Optimal Incentive Contract with Asymmetric Cost Information, Journal of Construction Engineering and Management 146, 040200542020.

[18] Yiu, T. W., Cheung, S. O., and Lok, C. L., A fuzzy fault tree framework of construction dispute negotiation failure, IEEE Transactions on Engineering Management 62, 171-1832015.

[19] Beaumont, B., Dispute Resolution in NEC3 - User Unfriendly?, Construction Law Journal 25, 591-6132009.

[20] Murphy, S. E., Spillane, J. P., Hendron, C., and Bruen, J., NEC Contracting: Evaluation of the Inclusion of Dispute Review Boards in lieu of Adjudication in the Construction Industry in the United Kingdom, Journal of Legal Affairs and Dispute Resolution in Engineering and Construction 6, 045140022014.

[21] Raj, S., Hillig, J. B., and Hughes, W., Responsiveness to change by standard-form contract drafters in the construction industry: A case study of the FIDIC White Book, International Journal of Law in the Built Environment 1, 205-220 2009.

[22] Rameezdeen, R. and Rodrigo, A., Modifications to standard forms of contract: The impact on readability, Australasian Journal of Construction Economics and Building $14,31-402014$.

[23] Mitropoulos, P. and Howell, G., Model for Understanding, Preventing, and Resolving Project Disputes, Journal of Construction Engineering and Management 127, 2232312001.

[24] Schuhmann, R. and Eichhorn, B., Reconsidering contact risk and contractual risk management, International Journal of Law and Management 59, 504-521 2017.

[25] Koc, K. and Gurgun, A. P., Assessment of Readability Risks in Contracts Causing Conflicts in Construction Projects, Journal of Construction Engineering and Management 147, 040210412021.

[26] Hassan, F. U. and Le, T., Automated Requirements Identification from Construction Contract Documents Using Natural Language Processing, Journal of Legal Affairs and Dispute Resolution in Engineering and Construction 12, 045200092020.

[27] Zakaluk, B. L. and Samuels, S. J., Readability, Its Past, Present, and Future. Newark, Delaware: The International Reading Association, 1988.

[28] Abotaleb, I. S., El-Adaway, I. H., and Moussa, M. B., Guidelines for Administrating and Drafting Nonpayment Owners' Obligation Provisions under Design-Build Contracts, Journal of Management in Engineering 35, 040190102019.

[29] Broome, J. C. and Hayes, R. W., A comparison of the clarity of traditional construction contracts and of the New Engineering Contract, International Journal of Project Management 15, 255-261 1997. 
[30] Lau, C. H., Mesthrige, J. W., Lam, P. T. I., and Javed, A. A., The challenges of adopting new engineering contract: a Hong Kong study, Engineering, Construction and Architectural Management 26, 2389-2409 2019.

[31] Youssef, A., Osman, H., Georgy, M., and Yehia, N., Semantic Risk Assessment for Ad Hoc and Amended Standard Forms of Construction Contracts, Journal of Legal Affairs and Dispute Resolution in Engineering and Construction 10, 045180022018.

[32] Lee, J., Ham, Y., Yi, J. S., and Son, J., Effective Risk Positioning through Automated Identification of Missing Contract Conditions from the Contractor's Perspective Based on FIDIC Contract Cases, Journal of Management in Engineering 36, 050200032020.

[33] Shi, L., He, Y., Onishi, M., and Kobayashi, K., Double Moral Hazard and RiskSharing in Construction Projects, IEEE Transactions on Engineering Management 1, 1-11 2019.

[34] Zeng, W., Wang, H., Li, H., Zhou, H., Wu, P., and Le, Y., Incentive Mechanisms for Supplier Development in Mega Construction Projects, IEEE Transactions on Engineering Management 66, 252-265 2019.

[35] Ameer Ali, N. A. N. and Wilkinson, S., Modernising Construction Contracts Drafting - A Plea for Good Sense, 2010.

[36] Chong, H. Y. and Oon, C. K., A practical approach in clarifying legal drafting: Delphi and case study in Malaysia, Engineering, Construction and Architectural Management 23, 610-621 2016.

[37] Menches, C. L. and Dorn, L., Emotional Reactions to Variations in Contract Language, Journal of Legal Affairs and Dispute Resolution in Engineering and Construction 5, 97-105 2013.

[38] Cutts, M., Oxford Guide to Plain English. New York: Oxford University Press, 2004.

[39] Chong, H. Y., Balamuralithara, B., and Chong, S. C., Construction contract administration in Malaysia using DFD: A conceptual model, Industrial Management and Data Systems 111, 1449-1464 2011.

[40] Clough, R. H., Sears, G. A., and Sears, S. K., Construction project management. New York: John Wiley \& Sons, 2000.

[41] Ameer Ali, N. A. N., Modern Plain English Drafting and Construction: the Malaysian Subcontract Model Terms, Society of Construction Law D90, 1-67 2008.

[42] Candlin, C. N., Bhatia, V. K., and Jensen, C. H., Developing legal writing materials for English second language learners: Problems and perspectives, English for Specific Purposes 21, 299-320 2002.

[43] Argyres, N. and Mayer, K. J., Contract Design as a Firm Capability: An Integration of Learning and Transaction Cost Perspectives, The Academy of Management Review 32, 1060-1077 2007.

[44] Azghandi-Roshnavand, A., Evaluation of construction contract documents to be applied in modular construction focusing ambiguities; A text processing approach, Concordia University, 2019. 
[45] Kumaraswamy, M. M., Consequences of Construction Conflict: A Hong Kong Perspective, Journal of Management in Engineering 14, 66-74 1998.

[46] Acharya, N. K., Dai Lee, Y., and Man im, H., Conflicting factors in construction projects: Korean perspective, Engineering, Construction and Architectural Management 13, 543-566 2006.

[47] El-adaway, I. H., Vance, R. A., and Abotaleb, I. S., Understanding Extension of Time under Different Standard Design-Build Forms of Contract, Journal of Legal Affairs and Dispute Resolution in Engineering and Construction 12, 045190312020.

[48] Costa, F., Denis Granja, A., Fregola, A., Picchi, F., and Portioli Staudacher, A., Understanding Relative Importance of Barriers to Improving the Customer-Supplier Relationship within Construction Supply Chains Using DEMATEL Technique, Journal of Management in Engineering 35, 040190022019.

[49] Liu, H. and Long, H., Identification of critical factors in construction and demolition waste recycling by the grey-DEMATEL approach: a Chinese perspective, Environmental Science and Pollution Research 27, 8507-8525 2020.

[50] Negash, Y. T. and Hassan, A. M., Construction Project Success under Uncertainty: Interrelations among the External Environment, Intellectual Capital, and Project Attributes, Journal of Construction Engineering and Management 146, 1-13 2020.

[51] Chileshe, N., Rameezdeen, R., and Hosseini, M. R., Drivers for adopting reverse logistics in the construction industry: A qualitative study, Engineering, Construction and Architectural Management 23, 134-157 2016.

[52] Zhang, X., Zhang, W., Jiang, L., and Zhao, T., Identification of Critical Causes of Tower-Crane Accidents through System Thinking and Case Analysis, Journal of Construction Engineering and Management 146, 040200712020.

[53] Nasirzadeh, F., Rostamnezhad, M., Carmichael, D. G., Khosravi, A., and Aisbett, B., Labour productivity in Australian building construction projects: a roadmap for improvement, International Journal of Construction Management 1, 1-10 2020.

[54] Zhou, S., Sun, J., Li, K., and Yang, X., Development of a Root Cause Degree Procedure for measuring intersection safety factors, Safety Science 51, 257-266 2013.

[55] Kumar, A. and Dixit, G., An analysis of barriers affecting the implementation of ewaste management practices in India: A novel ISM-DEMATEL approach, Sustainable Production and Consumption 14, 36-52 2018.

[56] Wang, D., Wang, X., Liu, M., Liu, H., and Liu, B., Managing public - private partnerships: a transmission pattern of underlying dynamics determining project performance, Engineering, Construction and Architectural Management 2020.

[57] Chen, C.-A., Using DEMATEL method for medical tourism development in Taiwan, American journal of tourism research 1, 26-32 2012.

[58] Lin, C. L. and Tzeng, G. H., A value-created system of science (technology) park by using DEMATEL, Expert Systems with Applications 36, 9683-9697 2009.

[59] Ghoddousi, P., Nasirzadeh, F., and Hashemi, H., Evaluating Highway Construction Projects' Sustainability Using a Multicriteria Group Decision-Making Model Based 
on Bootstrap Simulation, Journal of Construction Engineering and Management 144, 2018.

[60] Charkhakan, M. H. and Heravi, G., Risk Manageability Assessment to Improve Risk Response Plan: Case Study of Construction Projects in Iran, Journal of Construction Engineering and Management 144, 2018.

[61] Hasan, A., Elmualim, A., Rameezdeen, R., and Marshall, A., An exploratory study on the impact of mobile ICT on productivity in construction projects, Built Environment Project and Asset Management 8, 320-332 2018.

[62] Chang, B., Chang, C. W., and Wu, C. H., Fuzzy DEMATEL method for developing supplier selection criteria, Expert Systems with Applications 38, 1850-1858 2011.

[63] Li, C. W. and Tzeng, G. H., Identification of a threshold value for the DEMATEL method using the maximum mean de-entropy algorithm to find critical services provided by a semiconductor intellectual property mall, Expert Systems with Applications 36, 9891-9898 2009.

[64] Alzahrani, A. I., Al-Samarraie, H., Eldenfria, A., and Alalwan, N., A DEMATEL method in identifying design requirements for mobile environments: students' perspectives, Journal of Computing in Higher Education 30, 466-488 2018.

[65] Lee, P. T. W. and Lin, C. W., The cognition map of financial ratios of shipping companies using DEMATEL and MMDE, Maritime Policy and Management 40, 133-145 2013.

[66] Tzeng, G. H., Chiang, C. H., and Li, C. W., Evaluating intertwined effects in elearning programs: A novel hybrid MCDM model based on factor analysis and DEMATEL, Expert Systems with Applications 32, 1028-1044 2007.

[67] Barton, T., Berger-walliser, G., and Haapio, H., Visualization: Seeing Contracts for What They Are, and What They Could Become, Journal of Law, Business \& Ethics 19, 47-64 2013.

[68] Siegel, A. I., Lambert, J. V, and Burkett, J. R., Techniques for Making Written Material More Readable/Comprehensible, Texas, 1974.

[69] Yildizel, S. A., Dogan, E., Kaplan, G., and Ergut, A., Major Constructional Dispute Causes in Turkey, Archives of Civil Engineering 62, 193-204 2016.

[70] Jagannathan, M., Santosh, V., and Delhi, K., Litigation in Construction Contracts: Literature Review, Journal of Legal Affairs and Dispute Resolution in Engineering and Construction 12, 031190012020.

[71] Coyle, J. F., The Butterfly Effect in Boilerplate Contract Interpretation, Law and Contempopary Problems 82, 1-13 2019.

[72] Singh, R. and Bhanot, N., An integrated DEMATEL-MMDE-ISM based approach for analysing the barriers of IoT implementation in the manufacturing industry, International Journal of Production Research 58, 2454-2476 2020.

[73] Rameezdeen, R. and Rodrigo, A., Textual complexity of standard conditions used in the construction industry, Australasian Journal of Construction Economics and Building 13, 1-12 2013. 